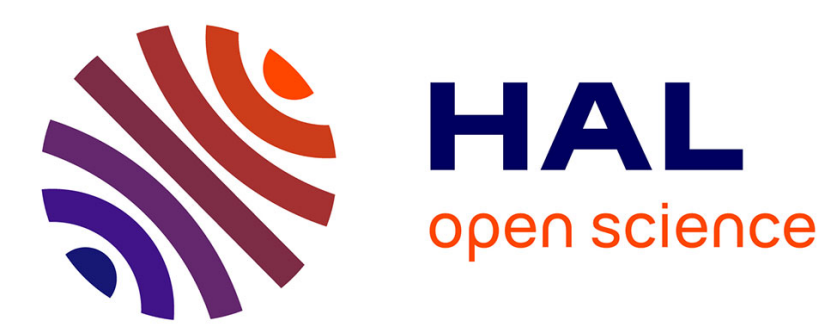

\title{
Ville et épidémiologie spatiale. Non-géographies de la COVID-19 en France?
}

\author{
Régis Darques, Julie Trottier
}

\section{To cite this version:}

Régis Darques, Julie Trottier. Ville et épidémiologie spatiale. Non-géographies de la COVID19 en France?. Villes en parallèle, 2020, Matériaux pour la ville de demain, 49-50, pp.121-156. 10.3406/vilpa.2020.1812 . halshs-03098706

\section{HAL Id: halshs-03098706 https://shs.hal.science/halshs-03098706}

Submitted on 8 Jan 2021

HAL is a multi-disciplinary open access archive for the deposit and dissemination of scientific research documents, whether they are published or not. The documents may come from teaching and research institutions in France or abroad, or from public or private research centers.
L'archive ouverte pluridisciplinaire HAL, est destinée au dépôt et à la diffusion de documents scientifiques de niveau recherche, publiés ou non, émanant des établissements d'enseignement et de recherche français ou étrangers, des laboratoires publics ou privés. 
Ville et épidémiologie spatiale. Non-géographies de la COVID-19 en France?

Régis Darques, Julie Trottier

\section{Citer ce document / Cite this document :}

Darques Régis, Trottier Julie. Ville et épidémiologie spatiale. Non-géographies de la COVID-19 en France ?. In: Villes en parallèle, $n^{\circ} 49-50,2020$. Matériaux pour la ville de demain. pp. 120-157;

doi : https://doi.org/10.3406/vilpa.2020.1812

https://www.persee.fr/doc/vilpa_0242-2794_2020_num_49_1_1812

Fichier pdf généré le 07/01/2021 


\title{
Résumé
}

La crise du SARS-CoV-2 et les confinements associés ont donné lieu à une diffusion massive de données statistiques et cartographiques. Information en temps réel et couverture spatiale généralisée ont été associées à des mesures de contrôle territorial. Les cartographies épidémiologiques à destination opérationnelle mises au point par les autorités ne sont pas exemptes de défauts. Faute de données suffisamment détaillées, les modèles de contamination développés par les épidémiologistes restent pratiquement «hors sol ». Les villes ont été identifiées très tôt comme zones à risque. Pourtant elles échappent presque totalement à l'analyse. De nouvelles méthodes d'identification des clusters doivent être développées. WaterCov est un projet pilote à visée méthodologique en milieu urbain à travers une analyse précise des traces virales dans les réseaux d'eaux usées.

\begin{abstract}
Town and spatial epidemiology - The current SARS-CoV-2 crisis and associated lockdowns have been managed through large-scale information campaigns. Real-time information and systematic spatial coverage provided opportunities for the application of unprecedented forms of territorial control. However, the authorities developed mapping tools that are not free from defects. In the absence of accurate databases, most epidemiological models about COVID-19 spread pattern might be considered "off-ground". Cities were early identified as risky places in terms of contamination potential although they remain largely unstudied. New methods of identifying clusters need to be developped. WaterCov is a pilot project, with the explicit goal of providing new insights into the current epidemiological situation of cities through the analysis of viral traces collected in sewerage networks.
\end{abstract}




\section{Régis DARQUES, Julie TROTTIER}

Résumé : La crise du SARS-CoV-2 et les confinements associés ont donné lieu à une diffusion massive de données statistiques et cartographiques. Information en temps réel et couverture spatiale généralisée ont été associées à des mesures de contrôle territorial. Les cartographies épidémiologiques à destination opérationnelle mises au point par les autorités ne sont pas exemptes de défauts. Faute de données suffisamment détaillées, les modèles de contamination développés par les épidémiologistes restent pratiquement "hors sol ». Les villes ont été identifiées très tôt comme zones à risque. Pourtant elles échappent presque totalement à l'analyse. De nouvelles méthodes d'identification des clusters doivent être développées. WaterCov est un projet pilote à visée méthodologique en milieu urbain à travers une analyse précise des traces virales dans les réseaux d'eaux usées.

Mots clés : ville, épidémiologie spatiale, cartographie, eaux usées, COVID19

Abstract : Town and spatial epidemiology - The current SARS-CoV-2 crisis and associated lockdowns have been managed through large-scale information campaigns. Real-time information and systematic spatial coverage provided opportunities for the application of unprecedented forms of territorial control. However, the authorities developed mapping tools that are not free from defects. In the absence of accurate databases, most epidemiological models about COVID-19 spread pattern might be considered "off-ground". Cities were early identified as risky places in terms of contamination potential although they remain largely unstudied. New methods of identifying clusters need to be developped. WaterCov is a pilot project, with the explicit goal of providing new insights into the current epidemiological situation of cities through the analysis of viral traces collected in sewerage networks.

Key words : city, spatial epidemiology, mapping, wastewater, COVID-19

Régis Darques est chargé de recherche au CNRS, à I'UMR ART-Dev. Géographe et géomaticien, spécialiste de traitements de données. Ses centres d'intérêt s'étendent aux systèmes complexes et à la théorie du chaos. Julie Trottier est directrice de recherche au CNRS, à l'unité PRODIG. Ses recherches intègrent l'étude des sciences et sociétés (STS) à la political ecology. 


\section{VILLE ET ÉPIDÉMIOLOGIE SPATIALE. NON-GÉOGRAPHIES DE LA COVID-19 EN FRANCE ?}

Régis DARQUES JUlie TROTTIER

À partir de mars 2020, la France s'est retrouvée confinée d'une façon drastique et sans précédent. Ses résidents assignés à domicile ont été autorisés à sortir uniquement pour une série de raisons précises mentionnées sur un formulaire où devait figurer l'heure de sortie. Ce document devait être présenté à tout agent de police qui le réclamait. Toute personne outrepassant la durée permise pour pratiquer un sport (une heure) ou éloignée de plus d'un kilomètre de son domicile (sauf exception, pour effectuer des courses ou se rendre à un examen médical, par exemple) était passible d'une amende.

Ce régime draconien s'est imposé en réaction à l'urgence sanitaire posée par l'épidémie de COVID-19 car les hôpitaux français menaçaient d'être débordés. De nombreuses questions subsistent à propos de la gestion publique de cette crise, comme l'a démontré par la suite l'enquête parlementaire sur le sujet. Cet article n'aborde qu'une seule question parmi toutes celles qui émergent : comment expliquer, malgré l'abondance de cartes présentées depuis mars 2020 , l'absence totale de véritable spatialisation de la propagation de la maladie par les autorités publiques dans leur réponse à la crise ? La France dispose d'instituts de recherche et d'universités qui font sa fierté. Elle possède des capacités de spatialisation fine de la 
propagation de l'épidémie. Utiliser ces capacités lui aurait permis d'éviter le confinement à l'échelle nationale. Ceci aurait été bénéfique pour l'économie, mais aussi pour l'éducation, puisque de nombreuses écoles auraient pu rester ouvertes. Nos autorités ont choisi de confiner massivement les habitants pour les isoler du virus au lieu d'essayer de cerner la répartition spatiale du virus afin de l'endiguer et $d$ 'isoler le virus des habitants. Ce choix interpelle car les conséquences économiques, sociales et sanitaires sont lourdes.

L'incapacité de spatialiser la propagation de l'épidémie est souvent justifiée par le fait que les seules données publiques concernant les personnes contaminées ou décédées de la COVID-19 les lient soit à l'hôpital où le diagnostic a été posé, soit au lieu où elles sont décédées. La prise en compte de la domiciliation par les statistiques nationales agglomérées, au moins pendant la première crise, est incertaine. Au niveau international, les cartes produites n'ont fait que reprendre les données recueillies dans des conditions hétérogènes par les pays concernés. Accepter l'idée que ces cartes illustrent la propagation réelle du virus dans l'espace revient à supposer qu'un virus est influencé par l'existence de frontières administratives ou internationales dans son processus de contamination. Face à l'absurdité d'une telle hypothèse, on a souvent conclu à l'impossibilité de spatialiser la propagation de la maladie.

Il convient de distinguer la maladie, les patients, le virus et les traces laissées par le virus dans l'espace. II est évidemment absurde d'imaginer une spatialisation de la propagation de la maladie par comptage du nombre de personnes diagnostiquées dans les hôpitaux au sein d'un département, puis par projection d'une uniformité graphique sur la totalité de ce département. Si les données ne sont pas domiciliées, le résident d'un département voisin peut très bien se faire diagnostiquer dans un hôpital, puis voir son diagnostic contribuer à la représentation d'un département où il ne réside pas. Par ailleurs, cette maladie se propageant par voie orale de personne à personne, il existe d'ordinaire des clusters très localisés au sein des départements, alors que de vastes zones de ces départements n’hébergent pas le virus. 
Face à de telles incohérences, il paraît beaucoup plus utile de détecter les traces laissées par le virus sur les territoires observés, puis de spatialiser ces traces et les lier aux données socioéconomiques correspondantes. Cette stratégie permet (1) de cartographier de façon fine la propagation du virus et (2) d'appréhender les variables socio-économiques qui accélèrent la diffusion ou, au contraire, la ralentissent. Ces informations sont infiniment précieuses pour les autorités publiques dans l'élaboration d'une réponse adéquate à la crise. Si l'on détecte des traces virales dans quelques îlots d'habitation seulement au sein d'une municipalité, il est logique que les autorités portent leur attention en priorité sur ces îlots et accompagnent les résidents en vue d'endiguer la propagation de l'épidémie. Cela peut se faire d'une multitude de manières: tests de dépistage, développement de pistes cyclables pour éviter la transmission liée aux transports en commun, aide aux personnes particulièrement vulnérables à la COVID-19, fourniture gratuite de masques et de produits viricides aux ménages démunis, etc. Pour le dire autrement, il est préférable de cartographier la propagation du virus lui-même plutôt que la répartition des personnes diagnostiquées.

Pourquoi donc ne pas avoir procédé à cette spatialisation ? Une méthode pour détecter les traces de virus dans les eaux usées a été publiée sous la forme d'un pre-print dès le 28 mars 2020 (Medema et al., 2020). Environ la moitié des personnes contaminées par le SARSCoV-2 excrètent des traces virales dans leurs selles (Chen et al., 2020)(Tang et al., 2020)(Wu et al., 2020). Bien qu'il ne s'agisse que d'une partie des personnes contaminées, ce groupe compte aussi bien des personnes asymptomatiques que des personnes présentant des symptômes. Etant donné la propension de cette maladie à se propager au travers de clusters, localiser les îlots d'habitation où sont excrétées ces traces virales permet donc d'identifier les zones de plus forte contamination.

Chercheurs au CNRS et à I'INRAE à Montpellier, nous avons formé dès le début du mois d'avril 2020 une équipe interdisciplinaire pour (1) détecter ces traces virales dans le réseau des eaux usées de Montpellier, (2) spatialiser ces traces à l'échelle de l'îlot d'habitation, 
(3) lier cette cartographie aux données socio-économiques géospatialisées de I'INSEE. Nous nous sommes fixé comme but de développer la méthode la moins chère possible afin que l'expérience puisse être reproduite dans des pays moins développés. Comme nous étions tous fonctionnaires de l'État, ce projet ne requérait qu'un budget relativement modeste (130 000 euros). L'idée était de réaliser une cartographie précise pendant un an sur l'ensemble du réseau des eaux usées de Montpellier, ville où nous étions basés. L'intérêt du projet était évident. Ce monitoring pouvait permettre d'éviter un reconfinement général en élaborant des réponses sur mesure, applicables aux seuls îlots d'habitation contaminés. Ce projet n'est toujours pas financé en décembre 2020. Étonnamment, notre initiative s'est heurtée à différents obstacles. Les oppositions à la mise en œuvre du projet ont été vives, à tel point que, malgré une campagne de mesures fructueuses réalisée aux mois de mai et juin, nos autorisations de prélèvement dans le réseau d'eau usée nous ont été temporairement retirées, sous la pression de certains acteurs locaux. Faute d'outil adéquat, la métropole de Montpellier subit aujourd'hui un second confinement " aveugle ", comme le reste de la France. L'ampleur de la crise sanitaire et ses conséquences socioéconomiques impliquent pourtant que des solutions ingénieuses soient développées. Les villes françaises, suspectes d'être des lieux privilégiés de propagation épidémique, ont plus que jamais besoin de ce projet. Pourquoi cette initiative est-elle restée inaboutie à ce jour?

L'étude des sciences et technologies a démontré depuis longtemps, sous l'impulsion de Michel Callon (1986) et Bruno Latour (1987), que la transformation d'un énoncé scientifique en un fait scientifique et l'adoption d'une technologie par une société dépendent de bien plus que de la rigueur de la méthode scientifique qui les a produites. Dans sa théorie de l'acteur-réseau, Latour considère que l'épaisseur relative d'un réseau d'acteurs et d'actants détermine le destin d'un énoncé scientifique ou d'une machine. II nous invite donc à explorer les réseaux qui se font les champions d'un énoncé scientifique pour comprendre comment cet énoncé parvient à un statut d'hégémonie. Plus tard, Sheila Jasanoff (2004) a 
développé le concept de coproduction initialement mis en avant par Latour. Elle a démontré que l'ordre social (notre régulation des interactions humaines) et l'ordre naturel (notre représentation de la nature) sont produits conjointement. Le concept d'épistémologie civique désigne les processus institutionnels au travers desquels une société décide de retenir certains énoncés scientifiques et d'en écarter d'autres afin d'arriver à une décision collective (Jasanoff, 2005). C'est exactement ce qu'il convient de faire ici. Ce processus implique de nous pencher sur les interactions entre les scientifiques qui ont élaboré le projet, ceux qui ont tout mis en œuvre pour que l'initiative ne voie jamais le jour, et les multiples acteurs avec lesquels ils ont interagi dans ce processus comme l'Agence Nationale de la Recherche, la Métropole de Montpellier, ses services de gestion de l'eau, la compagnie Véolia qui gère les eaux usées via un contrat d'affermage, etc.

Becher et Trowler (2001) ont étudié les disciplines académiques en tant que tribus, et assimilent le corpus de savoir qu'elles produisent à des territoires qu'elles occupent. Ces auteurs ont analysé la façon dont les disciplines académiques se lancent parfois dans des "expansions territoriales " sur les terres de leurs voisins. Le sujet qui nous concerne requiert une collaboration entre virologues (développement d'une méthode rigoureuse de détection des traces virales), géographes-géomaticiens (mise en œuvre d'une véritable cartographie), épidémiologistes et sociologues (intégration des variables qui accélèrent ou ralentissent la propagation du virus), et ingénieurs (prise en compte des fluctuations de débit et de contenu dans les réseaux d'eau usée). Les interactions entre disciplines ont effectivement joué un rôle crucial qu'il convient d'explorer.

Au sein de notre équipe, un respect réciproque s'est développé précocement entre participants. La collaboration impliquait un apprentissage mutuel des pratiques et une familiarisation avec les approches des uns et des autres, de sorte que nous sommes parvenus, sur la base d'un financement d'amorçage de 5000 euros accordés par le CNRS, à publier un premier article (Trottier et al., 2020) détaillant la méthode de détection élaborée par notre virologue ainsi que nos résultats préliminaires. Un second article 
collectif, focalisé sur la spatialisation de l'épidémie, est aujourd'hui en cours de publication. Une telle production réalisée avec un budget aussi ténu témoigne de la vitalité de l'équipe. En revanche, d'autres scientifiques ont pris ombrage de notre projet et ont déployé une énergie remarquable à l'empêcher de se réaliser. Dans un contexte d'urgence sanitaire, sur un mode concurrentiel, des collectifs de chercheurs ont déployé leur arsenal de défense pour préserver leurs périmètres $d$ 'intervention. Pressions individuelles, interférences multiples avec les partenaires du projet, désinformation, font partie des moyens employés couramment aujourd'hui dans le milieu de la recherche pour empêcher l'émergence de projets alternatifs. La diversité des approches et le dialogue interdisciplinaire cèdent ainsi régulièrement la place à des stratégies d'exclusion.

Malgré les multiples obstacles et pressions exercées, nous avons persisté et soumis notre projet à I'ANR Flash-COVID en prenant soin de le soumettre en anglais afin que la proposition puisse être évaluée par des experts étrangers, et non par un réseau concurrent. Malgré une évaluation positive, notre projet n'a pas été financé. On note donc une cascade d'échecs dont l'enchaînement laisse perplexe : refus d'utiliser les laboratoires publics et les fonctionnaires qui se portaient pourtant volontaires pour réaliser ce travail; refus de soutenir la technologie la plus rentable pour le contribuable; incapacité à comprendre l'importance et l'utilité d'une spatialisation effective de la propagation du virus. Un suivi prometteur des eaux usées en entrée de 150 stations d'épuration réparties à travers la France est aujourd'hui soutenu par l'État à travers un financement supérieur à 3 millions d'euros. Mais un monitoring des traces virales en entrée de station d'épuration ne permet pas de cartographier la propagation du virus dans l'espace situé à l'amont, à un niveau d'échelle adéquat pour appliquer des mesures ciblées (îlots d'habitation). Un monitoring qui considère villes et métropoles comme des ensembles homogènes, non-différenciés, implique une coproduction de l'ordre naturel et social validant ex-ante les solutions de confinement "aveugle " applicables sur l'entièreté d'une région ou du territoire national. 
Pour que la détection des traces virales débouche sur une véritable spatialisation de la maladie, des mesures doivent être réalisées à une échelle pertinente. II faut, comme notre projet le propose, remonter les réseaux d'égouts de bifurcation en bifurcation pour suivre l'augmentation de la concentration des traces virales jusqu'aux îlots d'habitation qui les produisent. Notre objectif est de restreindre l'analyse au niveau de l'îlot d'habitation pour deux raisons: cette stratégie permet (1) de conserver l'anonymat des personnes et (2) d'identifier une zone à traiter en priorité, même si une seule personne est contaminée.

Ce projet constitue l'archétype de ce que Jasanoff appelle l'épistémologie civique. II convient de comprendre quels processus institutionnels empêchent aujourd'hui la prise en compte de la géographie dans l'élaboration de la réponse publique à la crise sanitaire causée par le SARS-CoV-2. Sans cette incorporation, les mesures non ciblées spatialement demeureront les seules à être déployées. Des villes ou des régions entières continueront de subir des décisions contraignantes de confinement, alors que les dommages collatéraux associés à ces mesures sont insoutenables, non seulement pour l'économie mais pour le maintien d'un tissu social sain.

\section{Crise épidémiologique, injonctions politiques, désordres scientifiques}

Au-delà des modalités d'émergence des connaissances dans le milieu de la recherche, nous pouvons légitimement nous interroger sur les raisons de cette absence de la géographie sur la scène nationale et internationale. La question peut sembler paradoxale : les médias ont diffusé une marée de chiffres, cartes et autres graphiques à un rythme quotidien. Ce flot permanent est pourtant trompeur. Proposer des cartes comme instruments de communication, à l'appui d'autres documentations graphiques, ne signifie pas forcément que la démarche adoptée par les organismes officiels de l'État ou les institutions internationales soit proprement géographique.

Confrontées à un dilemme impossible -gérer l'inconnu-, et malgré l'expérience de plusieurs États asiatiques touchés précocement, les 
autorités ont souvent navigué à vue. Pour relever le défi, ou du moins pour légitimer des décisions d'urgence prises par défaut, en l'absence d'une connaissance suffisante des causes, effets, manifestations et facteurs de résilience d'un agent pathogène nouveau, la science a été convoquée et mise en avant. La mission confiée aux scientifiques et autres experts a été de fournir des réponses claires et rapides à l'appui desquelles des décisions stratégiques pouvaient être engagées. Les modalités et formes de cette injonction politique adressée aux milieux académiques sont très discutables et ont donné lieu à de vifs débats. La cacophonie qui en a résulté a dû être compensée par une stratégie de communication publique. La communication compensera les incertitudes scientifiques pour mieux dissiper le chaos.

Confronté aux cartographies d'urgence et aux zonages d'alerte, le grand public reçoit les messages officiels sans disposer des connaissances techniques et de l'appareillage conceptuel qui permettent de déconstruire l'information présentée. Beaucoup ignorent que les géographes, et parmi eux plus spécifiquement les géographes humanistes, ont massivement abandonné la carte au fil des révolutions techniques qui ont émaillé les trois dernières décennies, au moment même où la géomatique et les outils de traitement de l'information numérique entraient dans une phase de croissance exponentielle. Les raisons de cet abandon relèvent des aléas de l'histoire et de l'épistémologie de la discipline. Disons simplement que la géographie critique, post-structuraliste, a placé un point d'honneur à démonter l'édifice des cartographies autoritaires anciennes, pour laisser s'épanouir les représentations alternatives, participatives ou spontanées. Certains parmi ces géographes-sanscartes ont poussé l'expérience plus loin en abandonnant pratiquement toute expression graphique. Le résultat est un recul notable de la partie quantitative des sciences géographiques, et une relégation de la géomatique et de toutes les techniques associées vers d'autres horizons disciplinaires, davantage prompts à saisir les multiples opportunités offertes par les révolutions récentes (algorithmique, informatique, big data). Des disciplines traditionnellement non-spatiales (Boria, 2013; Darques, 2015) se sont 
donc tournées vers la géomatique, le plus souvent sous une forme sectorielle appauvrie.

Ainsi, pour mieux interpréter la scénographie statistique et cartographique déployée autour de la crise de la COVID-19, nous partirons de deux constats de base :

1 - Le modèle dominant aujourd'hui est celui des cartes mentales. La dimension appliquée, analytique et objective de la recherche a perdu énormément de terrain face aux études cognitives pour lesquelles les travaux positivistes sont suspects de partialité, voire de tricherie systématique (Dodge, Kitchin, \& Perkins, 2009; Wood, 2010; Wood \& Fels, 2008).

2 - Cette évolution ne saurait oblitérer la persistance d'usages anciens : les impostures cartographiques. La suspicion de partialité ou le mensonge systémique pèsent sur tous les documents graphiques produits dans des conditions non maîtrisées ou inexplicites (Huff, 1993; Monmonier, 1991, 2005), sans oublier les cas de fraude volontaire.

Pour résumer, la perte de crédibilité des cartes est telle que des usages objectifs sont souvent considérés comme impossibles. La crise de la COVID-19 est-elle une occasion de réhabiliter l'outil ou bien consacre-t-elle le pire des scénarios, celui d'un retour de la cartographie-propagande? De fait, la coproduction de la cartographie tout comme l'épistémologie civique qui déterminera l'usage de la cartographie échappent largement aux scientifiques impliqués dans ces recherches. La façon dont les interactions entre l'ensemble des acteurs engagés dans la lutte contre l'épidémie détermineront in fine l'usage de la cartographie émergera à l'issue de la crise sanitaire. L'histoire en train de s'écrire n'implique que de façon périphérique les scientifiques qui y sont impliqués.

\section{La logique du tableau de bord}

Depuis le début de l'épidémie et notamment à l'appui de décisions de confinement généralisé ou différencié, la plupart des organes de presse et services publics associés ont fait du nombre un élément d'information essentiel. Les chiffres pleuvent, les graphiques 
s'enchaînent, les cartes s'épandent et ce mécanisme est censé assurer la légitimité de mesures politiques d'urgence. La statistique $s^{\prime}$ impose comme un socle commun, elle édicte les bases d'une action politique contrainte à travers une aptitude paradoxale que l'on croit autoréalisatrice : produire l'harmonie par le calcul (Supiot, 2015).

L'exercice est risqué. Les statisticiens savent pertinemment que les manipulations mathématiques sur des séries de variables mal définies, issues de collectes peu maîtrisées, peuvent produire des catastrophes en cascade ou, à tout le moins, obscurcir la réalité plutôt que de l'éclairer. Or, dans la mêlée générale, amalgames et comparaisons indues ont proliféré, faisant fi de toutes les règles statistiques de base. Les observatoires ont mis en regard des données issues d'échantillons non représentatifs, collectées dans des conditions d'urgence, non normalisées, traitées selon des protocoles variables, sans tenir compte des biais multiples que la situation de crise aura nécessairement engendrés. Pouvait-on faire autrement ? Les bases de données rectifiées a posteriori qui sont aujourd'hui mises à disposition du public nous permettront-elles un jour de cerner le phénomène COVID-19 dans sa complexité réelle ? Rien n'est moins sûr.

Cette situation délicate soulève clairement la question de l'initiative politique à l'origine de tout dispositif d'observation scientifique :

- À l'international, seules des autorités intergouvernementales pourraient harmoniser les objectifs, définir les méthodes et assurer une collecte d'information cohérente et efficace. Au cours de cette crise, ces autorités, elles-mêmes mises en cause dans leur légitimité, n'ont pas réussi à prescrire des protocoles stricts. Cet échec n'a pourtant pas entravé la prolifération de statistiques internationales, dont l'utilité intrinsèque n'est pas discutable, mais dont la significativité reste extrêmement limitée faute de cohérence interne.

- On pourrait s'attendre, au niveau national, à des résultats plus probants. Certains pays ont, à ce qu'il semble, réussi à appliquer des protocoles de collecte et de traitement de l'information 
statistique efficients. D'autres ne sont pas parvenus à mettre en place des systèmes d'observation performants, ou l'ont fait tardivement. Les hypothèses que l'on peut poser à l'appui de cette impréparation systémique sont multiples et vont de l'affaiblissement chronique des États dans leur capacité à apparier souveraineté et contrôle des territoires à l'option inverse, à un sur-contrôle étatique de l'information qui interfère dans les processus de production statistique au point de les rendre inefficients ex ante. Une autre hypothèse consacre la montée en puissance d'un biopouvoir (Michel Foucault) capable de contrôler totalement la population au nom de la santé publique.

- Enfin, le niveau local semble avoir été particulièrement malmené. L'information géographique et statistique s'est déployée aux échelles supérieures, mais les initiatives locales observatoires, enquêtes, recensements, missions d'observation ont été marginales, avec des conséquences importantes en termes de gestion de crise : le jacobinisme, relayant certaines logiques de globalisation, a joué à plein.

\section{Du chiffre à la carte. Les errements d'une cartographie d'urgence (échelle internationale)}

Au-delà du phénomène statistique, la transposition cartographique de données dégradées a souvent débouché sur des représentations sauvages. Du chiffre à la carte, il existe un fossé que d'aucuns ont franchi... en s'affranchissant des contraintes qui prévalent pour ce type d'exercice. Représentations biaisées, maladroites, tendancieuses ou parfois entièrement fausses se sont propagées massivement. La diffusion à grande échelle de cartes automatiques élaborées par des non-spécialistes a renforcé la confusion plutôt que l'analyse. Ceci appelle une herméneutique spécifique.

Notre attention ne portera pas sur les dérives habituelles de production et d'usage de la carte. Les documents graphiques mis en avant pendant cette crise s'inséraient forcément dans une façon de 


\section{France?}

penser la gestion de cette même crise. La carte est ainsi appelée à s'affranchir régulièrement du réel, à le remodeler; elle devient un outil de gouvernance porteur de visions prospectives ou rétrospectives du monde (Black, 1997; Crampton, 2001; Monmonier, 1991; Olsson, 2007). Quelques parutions intéressantes ont déjà vu le jour à propos des incongruités cartographiques que la crise du SARSCov-2 a produites (Bbcworld, 2020; Genevois, 2020; Geraghty \& Estella, 2020).

À titre d'exemple, nous aborderons dans un premier temps la cartographie épidémiologique internationale. Au niveau mondial, des données ont été collectées assez tôt. L'OMS fait commencer ses séries statistiques relatives à la pandémie au 11 janvier 2020 (World Health Organization, 2020b). À l'aval, des plates-formes web dynamiques émergent rapidement. Ce phénomène est rendu possible par une structure simplissime des bases de données primaires: I'approche est mondiale, les fonds vectoriels s'appuient sur les limites de pays ou d'États (fédérations); les données sont épidémiologiques et démographiques. Nombre total de cas confirmés, cas actifs, taux d'incidence, taux de létalité, taux de tests, taux d'hospitalisation sont parmi les indicateurs adoptés (JohnsHopkins, 2020). 


\section{Régis DARQUES, Julie TROTTIER}

Figure 1. Johns Hopkins Coronavirus Resource Center

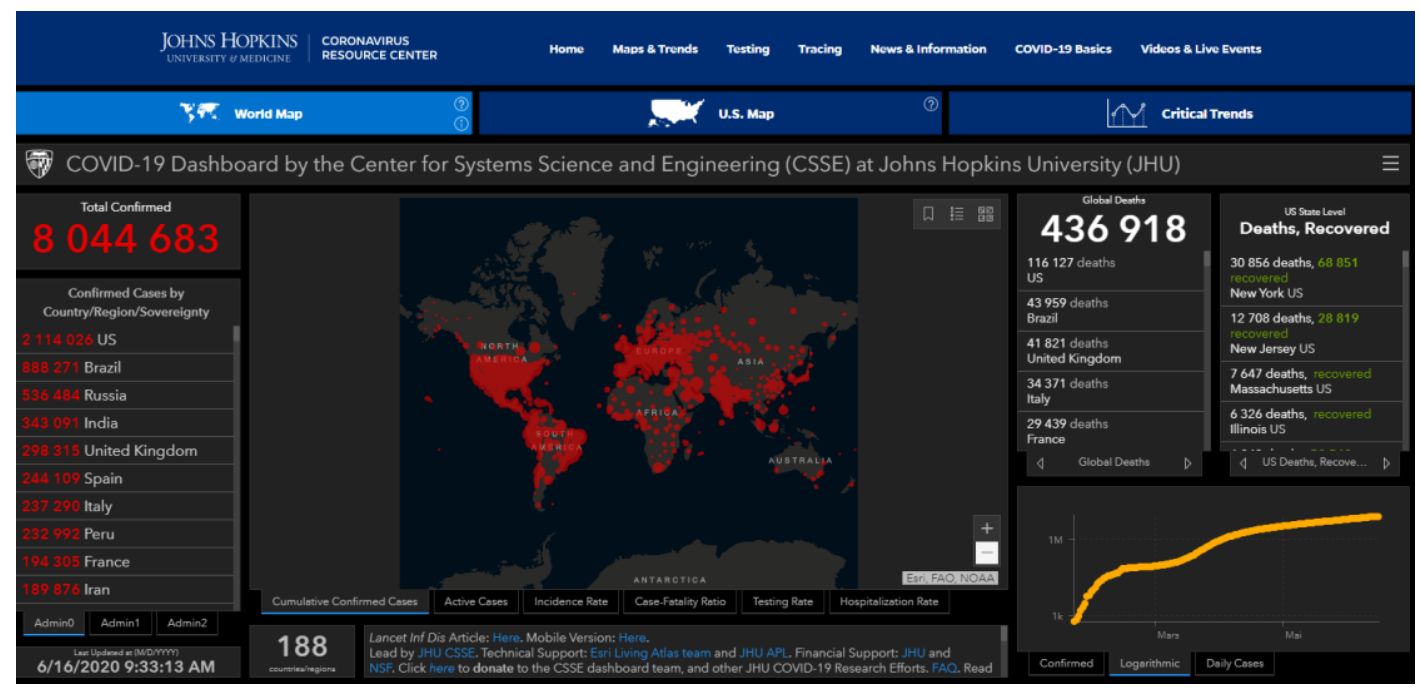

Source : Johns Hopkins University and Medicine

Cette représentation sur fond sombre et le principe d'une mise en parallèle des chiffres bruts et de la carte ont été largement repris ou adoptés par d'autres sites. Le positionnement d'un centre de cartographie universitaire dans l'étude de la pandémie n'est pas anodin. L'université assume ici un rôle d'information du grand public réservé dans d'autres pays à des organes de communication gouvernementaux, exclusivement. Les échelles inférieures sont uniquement disponibles pour les États-Unis. Le tableau de bord est mis à jour automatiquement et quotidiennement. Le "poids des chiffres" est ici essentiel, et l'approche critique des sources (fiabilité, comparabilité et significativité des données) est volontairement laissée de côté. 


\section{Ville et épidémiologie spatiale. Non-géographies de la COVID-19 en}

France?

Les représentations peuvent parfois être moins classiques et plus dynamiques, mais le principe reste le même (Worldmapper, 2020).

Figure 2. COVID-19 Map Animation 21.01.2020-07.06.2020

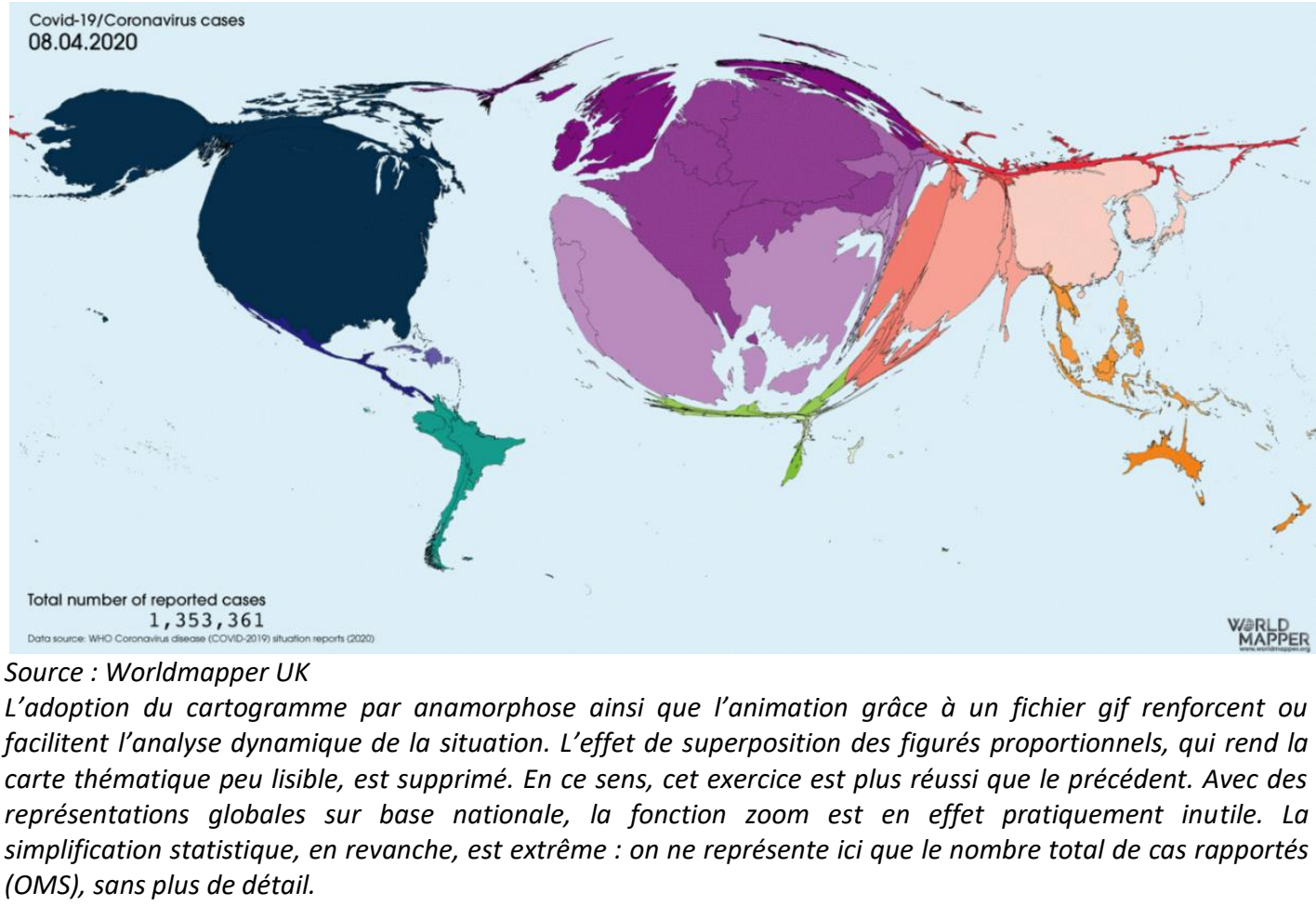

Bref, la représentation brute prend le dessus sur l'analyse des données. Pour cerner les limites de l'exercice, il faut se reporter aux annexes des rapports de mise à disposition de l'OMS, par exemple (World Health Organization, 2020a) :

"Caution must be taken when interpreting all data presented. Differences are to be expected between information products published by WHO, national public health authorities, and other sources using different inclusion criteria and different data cut-off times. While steps are taken to ensure accuracy and reliability, all data are subject to continuous verification and change. Case detection, definitions, testing strategies, reporting practice, and lag times differ between countries/territories/areas. These factors, amongst others, influence the 
counts presented, with variable underestimation of true case and death counts, and variable delays to reflecting these data at global level".

De l'aveu même de l'OMS, les variations et aléas de production des données primaires rendent toute interprétation... improbable. Nous sommes ici très loin des critères d'acceptabilité usuels dans la constitution des séries statistiques. Ce phénomène de distorsion différentielle est connu pour les données internationales en général, devenues au fil des ans, en dépit de leurs multiples défauts, d'usage d'autant plus courant que leur fiabilité n'a jamais été autant discutable ou discutée.

Cet amateurisme systémique se traduit ensuite fréquemment par une cartographie tout aussi approximative.

Figure 3. Nombre de cas confirmés de COVID-19 rapportés au cours des sept derniers jours par pays, territoire ou zone, 6 au 12 juin

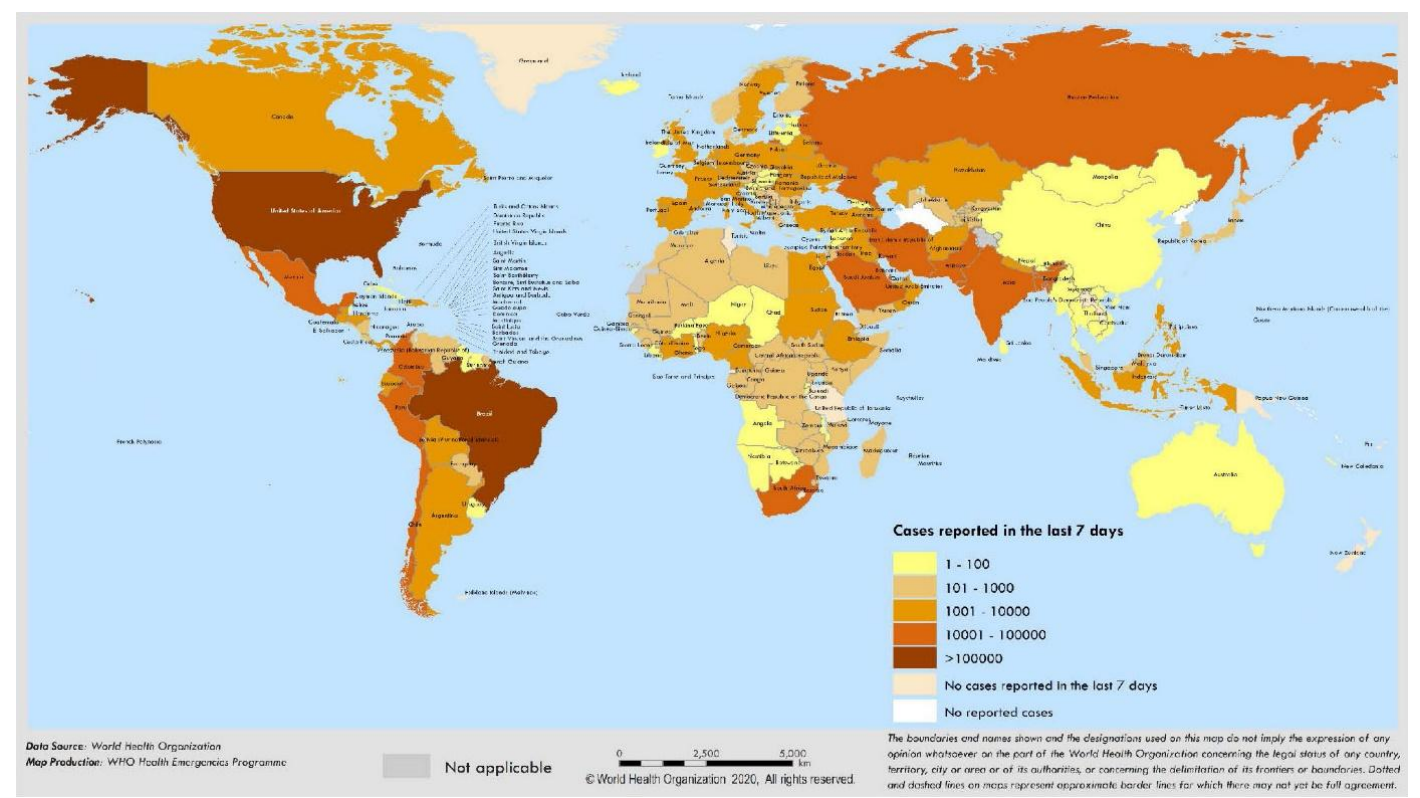

Source : OMS

Ici, les règles primaires de sémiologie graphique et de représentation statistique ont été négligées. Les données brutes ne peuvent jamais être représentées par plage -carte dite choroplèthe-, mais seulement par symboles proportionnels. La discrétisation semble également peu optimisée. Ce type de cartographie erronée a proliféré, preuve des dérives de l'usage de SIG mal maîtrisés. Forme et fond sont donc tronqués, ce qui rend très délicate l'utilisation de ce type de document. 
Ainsi, à travers ces représentations mal calibrées, on constate que le processus d'épistémologie civique qui s'est déroulé dans l'urgence a vu de nombreux acteurs au sein des médias, des autorités publiques et de la recherche retenir des énoncés scientifiques facilement invalidés par la méthode scientifique. Des énoncés non validés par la méthode scientifique sont ainsi devenus des faits scientifiques largement partagés. Ce phénomène n'est ni rare ni anachronique. II importe d'explorer ce processus d'épistémologie civique pour comprendre les processus qui empêchent actuellement la prise en compte de la spatialisation de l'épidémie à une échelle appropriée dans l'élaboration des politiques publiques.

\section{France : inadaptation des dispositifs statistiques officiels?}

En France, pendant la crise, l'analyse épidémiologique a essentiellement relevé du gouvernement et de ses relais locaux. D'un point de vue politique, cette situation révèle la persistance, à l'heure du retour au local, d'un contrôle centralisé dont on trouve peu d'équivalents à l'étranger. Le schéma institutionnel est assez clair : les hôpitaux, EHPAD et EMS fournissent les données primaires, puis les ARS relaient l'information (Occitanie, 2020) qui est finalement transmise au ministère des Solidarités et de la Santé (Santé Publique France, 2020a). Le site Etalab indique que (Etalab, 2020) :

«Le défi a été de parvenir à collecter et à consolider d'importants volumes de données issues de sources différentes. [...] Si des systèmes d'information nationaux existaient déjà, il a cependant été nécessaire de les adapter pour réaliser un suivi spécifique des patients atteints de Covid-19».

Le référentiel primaire du dispositif est le patient, c'est-à-dire la personne traitée par le dispositif médical (assimilé ipso facto au malade), non pas la personne contaminée. Le patient est pris en charge par la santé publique tandis que la personne infectée, symptomatique ou asymptomatique, reste hors champ institutionnel. Cette dernière n'apparaîtra pas dans les statistiques, ou de manière très indirecte. Le patient peut n'être pas infecté et, inversement, la 
personne infectée -a fortiori asymptomatique- peut ne jamais se transformer en patient. Étant donné la situation de crise et le risque de contamination associé aux consultations de tous ordres, des cohortes de porteurs du virus n'ont jamais été recensées. Pour passer du patient à une logique démographique plus globale, seul moyen de produire un taux de prévalence générale robuste, la procédure conforme à la méthode scientifique consiste à généraliser les tests de dépistage à l'ensemble de la population ou à un échantillon significatif de cette population, en tenant compte de paramètres géographiques et en introduisant une composante aléatoire. Or, ces tests n'ont été pratiqués en France qu'à la marge et de façon désordonnée, même lorsque les tests se sont multipliés.

La capacité analytique de tests virologiques est fournie par deux bases de données successives fournies par Santé publique France: les données relatives aux tests de dépistage de COVID-19 réalisés en laboratoire de ville (jusqu'au 29 mai) ; et le Système d'Informations de Dépistage (SI-DEP) qui prend le relais du précédent à partir du 13 mai. Données hospitalières et données issues des laboratoires de ville étaient donc dissociées au cours de la première période de confinement. Depuis, les données de tests ont été agglomérées, avec pour conséquence une incapacité à comparer les données de la première vague avec celles de la seconde. Très peu d'informations sont ainsi fournies à propos du dispositif de ville, mis à part une liste sèche de laboratoires, et sans que l'on puisse mesurer la montée en puissance progressive du dispositif de dépistage non hospitalier.

Le site du gouvernement indique que le 11 mai, date du début de la phase 1 du premier déconfinement, le nombre total de tests pratiqués en France depuis le début de la crise en laboratoires de ville s'élevait à 322000 , soit $0,48 \%$ de la population nationale (sans élimination des redondances). Les données de la nouvelle base SIDEP ne permettent pas de comparaison avec les chiffres précédents. Toutefois, la montée en puissance du dispositif de dépistage est remarquable. Entre le début du mois de mai 2020 et novembre de la même année, le nombre quotidien de tests est passé de 50000 à 300000 . Le nombre total cumulé de tests pratiqués au 9 novembre 2020 se monte à 17,5 millions (total sur six mois). 
Le taux de positivité proposé par Santé publique France ne doit pas être confondu avec le taux de prévalence général. II se rapporte en effet au nombre de personnes testées, pas à la population dans son ensemble. Rien n'indique que le groupe personnes testées soit représentatif de la population générale faute d'échantillonnage adapté et de prise en compte des redondances. La confusion est fréquente, mais les autorités ont pleinement conscience de cela: elles ne proposent dans leurs bases de données qu'un taux d'incidence (nombre de nouveaux cas observés), jamais un taux de prévalence général. II y a scission entre logique épidémiologique (référentiel patient) et démographie (référentiel population, recensement).

Lorsque les données de l'INSEE sont introduites, marginalement, il n'est pas tenu compte des déplacements, notamment ceux induits par les séjours prolongés de propriétaires de résidences secondaires loin de leur domicile lors des confinements. Une incertitude pèse également sur le bon référencement géographique des personnes diagnostiquées ou testées: diverses erreurs sont rapportées par Santé publique France, quant à l'enregistrement des patients par rapport à leur lieu de résidence ou au lieu de diagnostic, au moins dans la phase initiale de constitution des bases de données.

Au-delà des tests, la ressource la plus essentielle est hospitalière. Les premières données relatives aux hospitalisations sont récoltées début mars, avec près de deux mois de décalage par rapport à l'OMS. Les chiffres sont très approximatifs au départ. Il s'agit en priorité de relever les décès confirmés par un test positif et les patients placés en réanimation selon une logique ascendante: on comptabilise d'abord les décès, puis la chaîne d'information remonte vers les patients nécessitant des soins en réanimation, puis vers ceux pris en charge par les services hospitaliers hors réanimation. Cette logique d'entonnoir perdure aujourd'hui. L'attention se focalise sur les services hospitaliers en priorité, et le niveau de vigilance (ou de connaissance) s'atténue à mesure que l'on s'éloigne des hôpitaux.

On trouve ici une indication importante concernant la participation de l'ordre social à la coproduction de la cartographie de crise. Si un gouvernement souhaite maintenir le financement des 
hôpitaux dans son état actuel, il importe d'essentialiser le nombre de lits disponibles, tout en présentant ces lits comme des éléments indispensables du dispositif sanitaire. La stratégie consiste in fine à mettre la population à disposition des hôpitaux plutôt que les hôpitaux à disposition de la population, sans que cette politique ne puisse être remise en question. Les hommages rendus au personnel soignant ont participé à ce processus de coproduction tout comme la manière dont le ministre de la Santé, relayé par les médias, s'est focalisé sur le nombre de lits de réanimation encore disponibles. En focalisant l'approche chiffrée sur les hôpitaux, on coproduit une représentation des solutions à la crise qui fait apparaître comme incontournable le renoncement aux libertés fondamentales lié aux confinements.

Diverses erreurs sont rapportées par le ministère, qui indique de façon liminaire que :

"le système de déclaration des cas n'est pas exhaustif et le nombre d'établissements déclarant varie au cours du temps ».

II ne s'agit pas seulement de formules prudentielles. Les chiffres ont été soumis à des révisions et corrections diverses, parfois massives, à mesure que le dispositif statistique se mettait en place et se consolidait.

\section{Les cartographies, outils de communication}

La cartographie officielle française est produite selon le même processus standardisé que celui relevé à l'international. Trois sites web principaux, largement repris par la presse, sont chargés de la diffusion (Gouvernement.fr, 2020; Santé Publique France, 2020b, 2020c). Un quatrième site-relais peut être mentionné (Ministère des Solidarités et de la Santé, 2020). 


\section{Ville et épidémiologie spatiale. Non-géographies de la COVID-19 en France?}

Figure 4. Vue d'ensemble France. Carte des hospitalisations

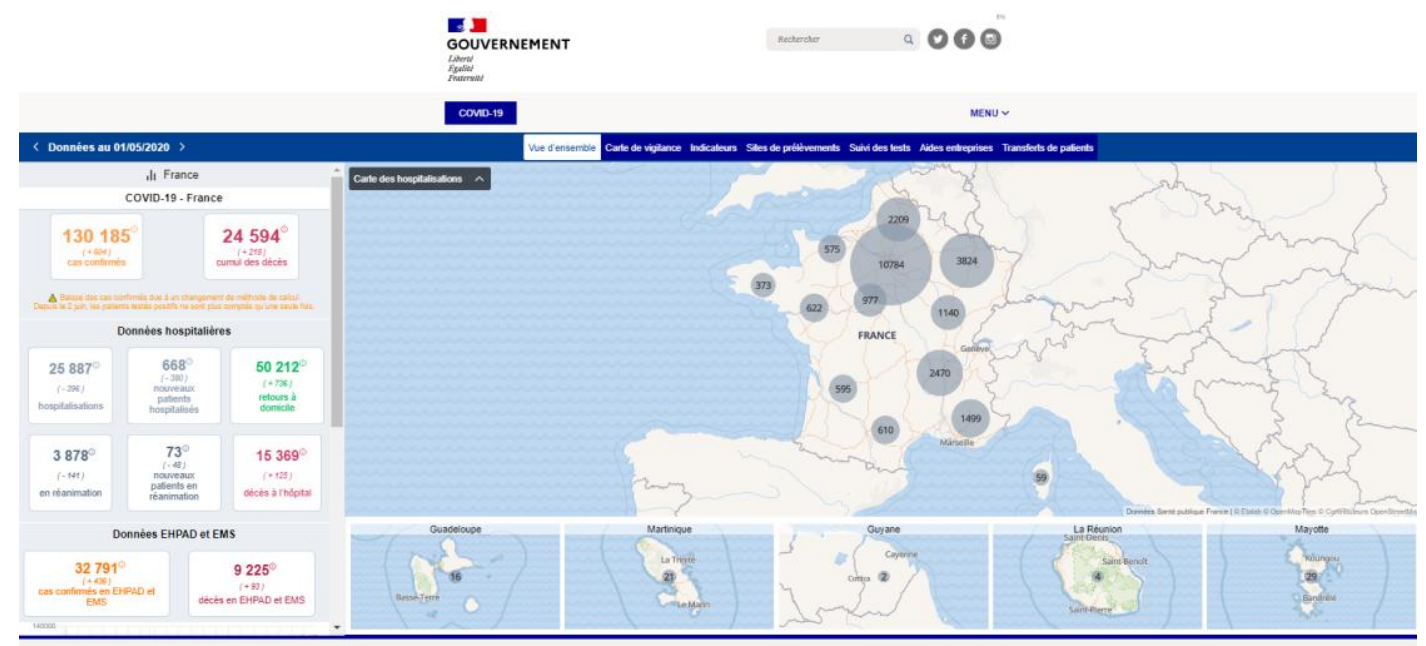

Source : Gouvernement.fr, $1^{\text {er }}$ mai 2020

Le tableau de bord général met à nouveau en relation chiffres et carte. Un code couleur est appliqué pour alerter les lecteurs. Le site indique que "l'information officielle sur la progression de l'épidémie en France est consolidée par Santé publique France ". La plate-forme numérique ne permet pas de remonter dans le temps au-delà du 2 mars 2020 (tableau général) ou du 18 mars (carte de vigilance).

Figure 5. Tableau de bord Géodes infra-départemental
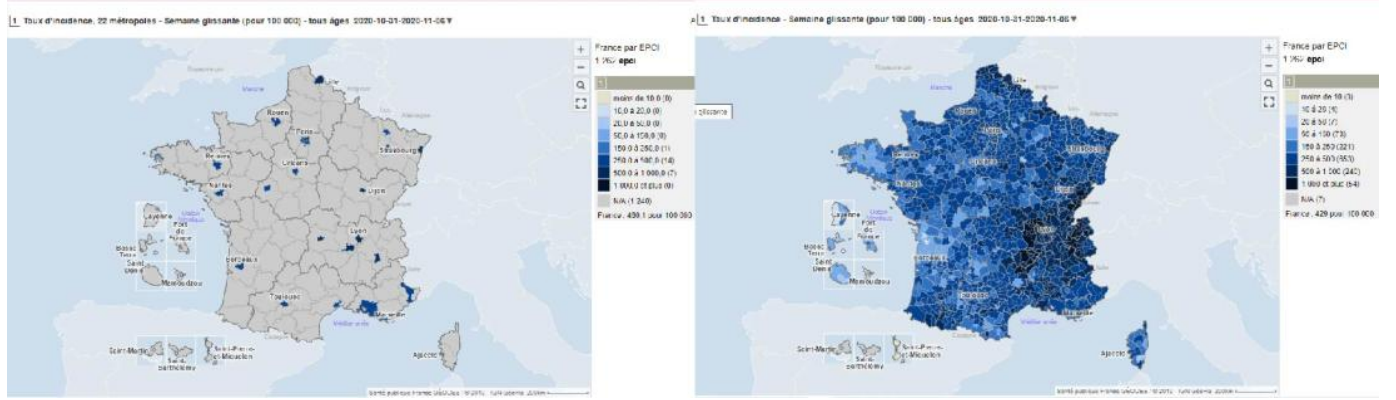

Source : Geodes, Sante Publique France, semaine du 31 octobre au 6 novembre 2020

Les données infra-départementales sont disponibles depuis le 7 octobre 2020. Pour la première fois, des indicateurs sont publiés pour les métropoles. Cet "élémentaire urbain " a toutefois peu de place, puisque 22 métropoles seulement sont identifiées et dissociées du reste du territoire. Les données ne sont fournies qu'en valeur relative, rapportées à la population présente lors du recensement de 2017. Un redressement statistique est opéré (estimation de la population en 2020). La géolocalisation se fait au domicile de la personne testée. Toutefois, Santé Publique France indique que dans $25 \%$ des cas, le code postal ne permet pas de retrouver le code IRIS de résidence. Pour corriger ce biais, une "imputation " est appliquée : la répartition géographique des personnes se fait sur un principe probabiliste. 
Dans l'approche cartographique officielle, l'administration territoriale imprime sa marque. Jusqu'au mois de novembre, les données n'étaient rendues publiques qu'au niveau régional et départemental. Seules deux informations spécifiques dérogeaient à la règle et permettaient de cerner très partiellement les enjeux de la collecte des données géospatiales à échelon infra-départemental :

- Le site de prélèvements des tests virologiques RT-PCR : 3080 sites grand public et 139 sites d'accès restreint étaient référencés au $1^{\mathrm{er}}$ mai 2020 (3276 et 182 début novembre 2020) -pour la plupart des laboratoires d'analyse biomédicale, privés ou publics.

- Aucune cartographie des établissements de santé de $1^{\mathrm{re}}, 2^{\mathrm{e}}$, ou $3^{\mathrm{e}}$ ligne pour la prise en charge des patients n'est véritablement établie. II faudra chercher l'information auprès des ARS au cas par cas ou se référer, par exemple, aux outils mis en place par la presse (Ouestfrance, 2020) : 183 établissements de $1^{\text {re }}$ et $2^{\mathrm{e}}$ ligne sont désignés, mais la liste reste incertaine et le principe d'accueil des malades en hôpital reste opaque (proximité du domicile, équipement, capacités en lits, capacités en réanimation ?).

Comme on peut aisément le constater, le local est presque totalement absent du dispositif sanitaire hexagonal. II apparaît seulement en creux. 
Ville et épidémiologie spatiale. Non-géographies de la COVID-19 en France?

Figure 6. Sites de prélèvements

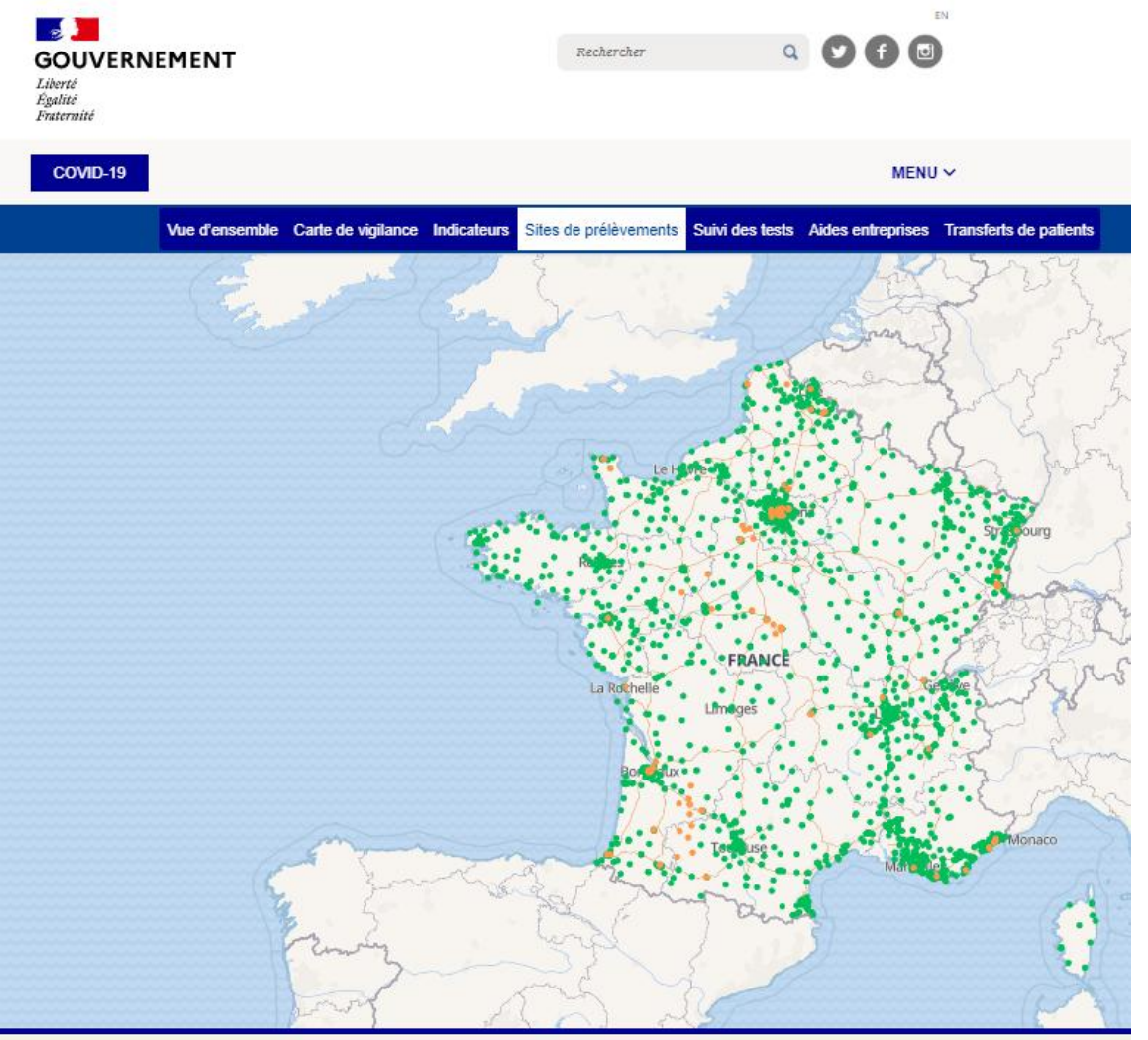

LE GOUVERNEMENT AGIT POUR VOUS.

Source : Gouvernement.fr, novembre 2020 


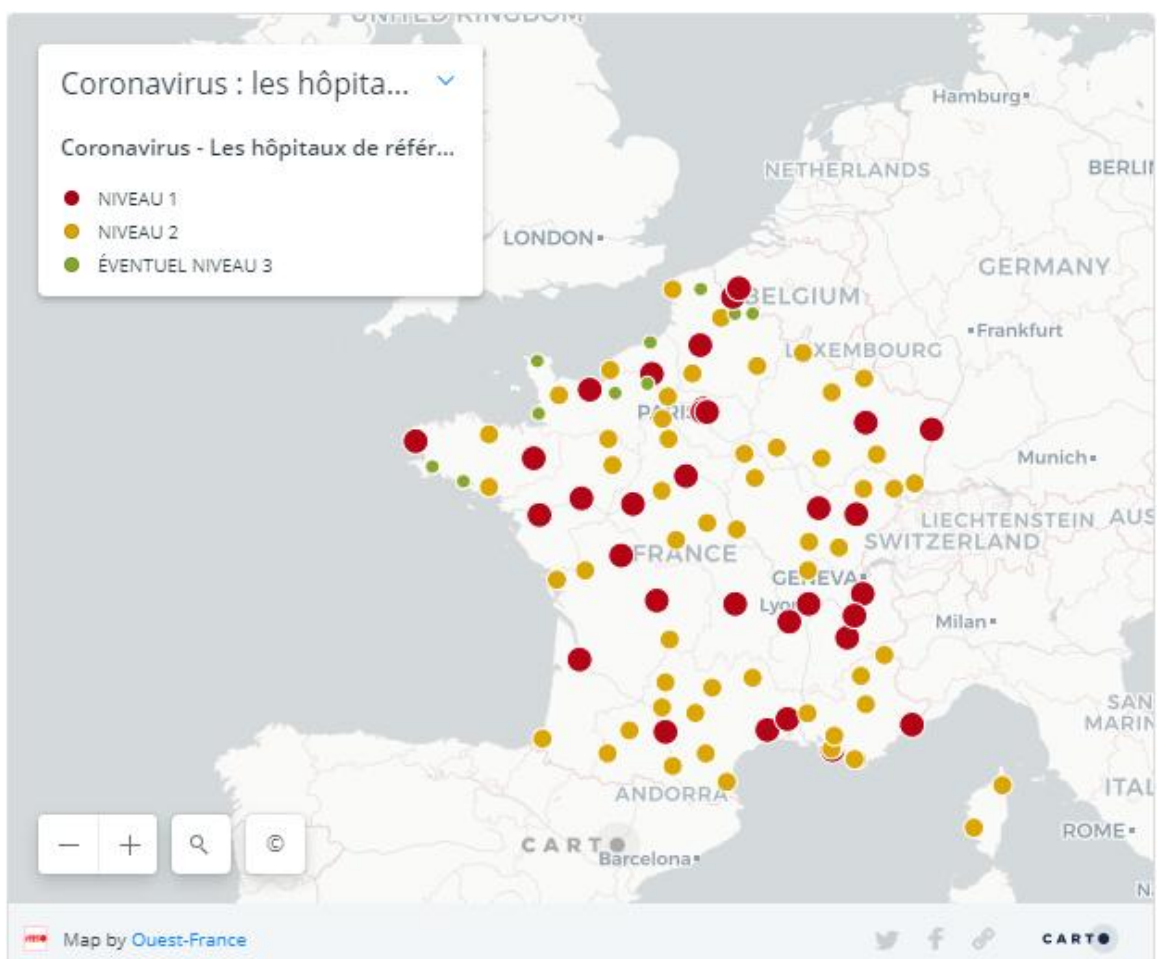

Source : Ouest France, 27 février 2020

L'essentiel de la communication se fonde sur des documents synthétiques élaborés à partir d'indicateurs ciblés: activité épidémique, taux de positivité des tests virologiques, $\mathrm{R}$ zéro, tension hospitalière, nombre de clusters. Carte de vigilance, zones d'alerte, puis couvre-feu se succèdent, adoptent des formats graphiques similaires ou des codes couleur différenciés, mais le principe d'ensemble reste le même: les indicateurs dérivés des bases de données sont eux-mêmes compilés pour produire une classification des départements qui définit à l'aval les niveaux de contrainte sanitaire correspondants. Comme pour tous les méta-indicateurs, les effets de seuillages différentiels cumulés peuvent produire des résultats parfois déroutants. À travers ce mécanisme, la cartographie acquiert une dimension opérationnelle et politique en se recentrant systématiquement sur le maillage départemental. 
Ville et épidémiologie spatiale. Non-géographies de la COVID-19 en France?

Le maillage administratif joue ici un rôle crucial dans la coproduction de la représentation de la propagation de l'épidémie. L'ordre social a donc joué un rôle déterminant dans la coproduction de la cartographie de l'épidémie. Le maillage départemental qui gouverne le système de santé permet une représentation graphique compatible avec le confinement de départements entiers. L'efficacité (discutable) de l'appareil d'État a donc primé, malgré l'invalidation scientifique de la méthodologie cartographique officielle.

Figure 8. Carte de vigilance (30 avril-15 juin)

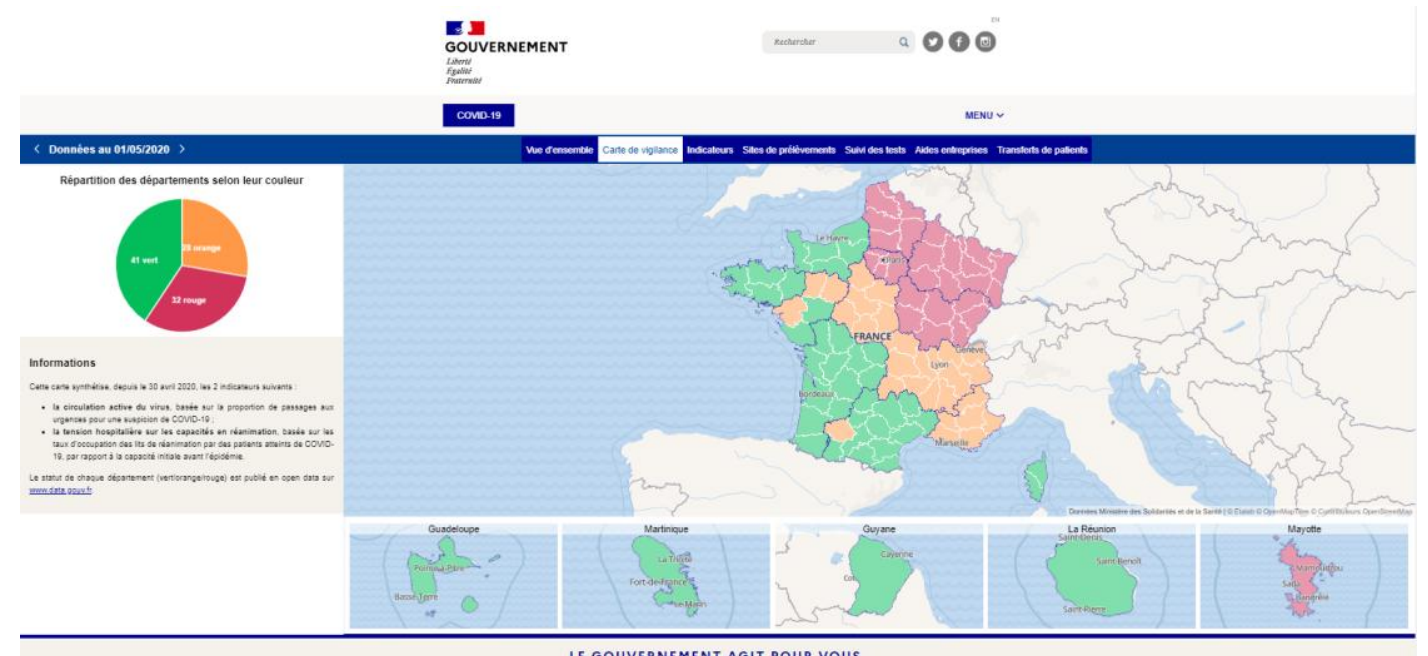

LE GOUVERNEMENT AGIT POUR VOUS.

Source : Gouvernement.fr, $1^{\text {er }}$ mai 2020

Cette carte se veut une synthèse de la situation épidémiologique au niveau national. Comme on peut le constater, les nouvelles régions imposent leur logique, à de rares exceptions près. Le basculement entre catégories se fait le plus souvent par blocs. Les indicateurs retenus pour l'élaboration de ces cartes ont évolué plusieurs fois. 

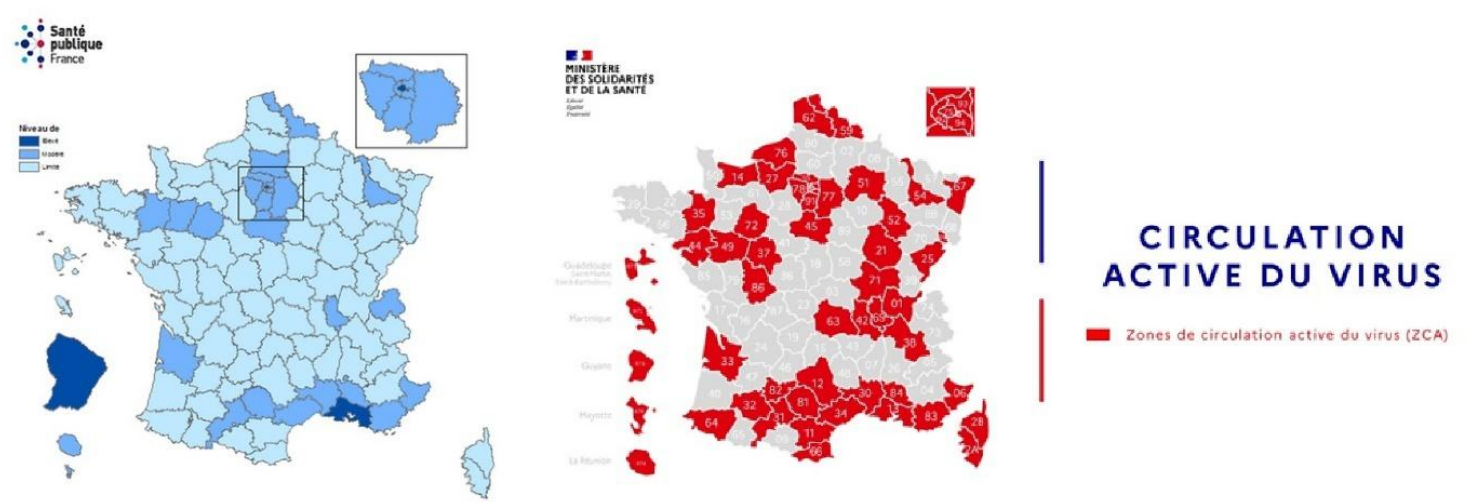

Source : Santé Publique France, Ministère des Solidarités et de la Santé, 19 août et 19 septembre 2020

La première représentation a une visée analytique et introduit trois niveaux intermédiaires d'alerte (limitée, modérée, élevée) à partir des indices déjà identifiés, plus le nombre de clusters. La seconde est binaire et sa vocation juridique. De fait, l'ensemble du territoire reste sous observation permanente. Les zones vertes, non suspectes, disparaissent, ainsi que le maillage régional. Les départements sont "autonomisés 》: les mesures de restriction prises par les préfets s'appliquent au niveau local. Insidieusement, la cartographie entérine l'idée d'une crise permanente. 
Ville et épidémiologie spatiale. Non-géographies de la COVID-19 en France?

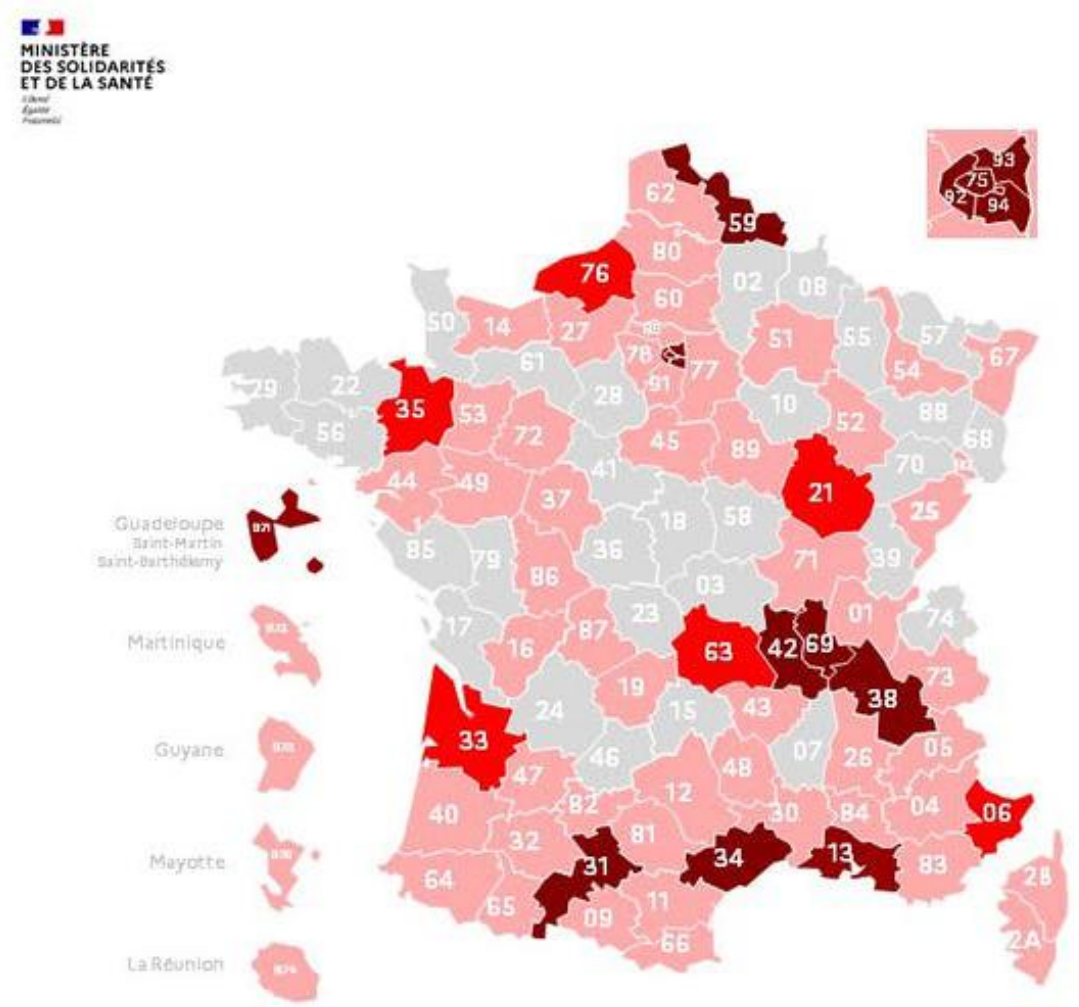

Source : ministère des Solidarités et de la Santé, 12 octobre 2020

Avec le renforcement de la menace sanitaire, le gouvernement instaure une nouvelle classification à cinq niveaux : gris (zone de vigilance), rose (zone d'alerte), rouge (zone d'alerte renforcée), rouge écarlate (zone d'alerte maximale). Une couleur noire complète le dispositif (état d'urgence sanitaire). 


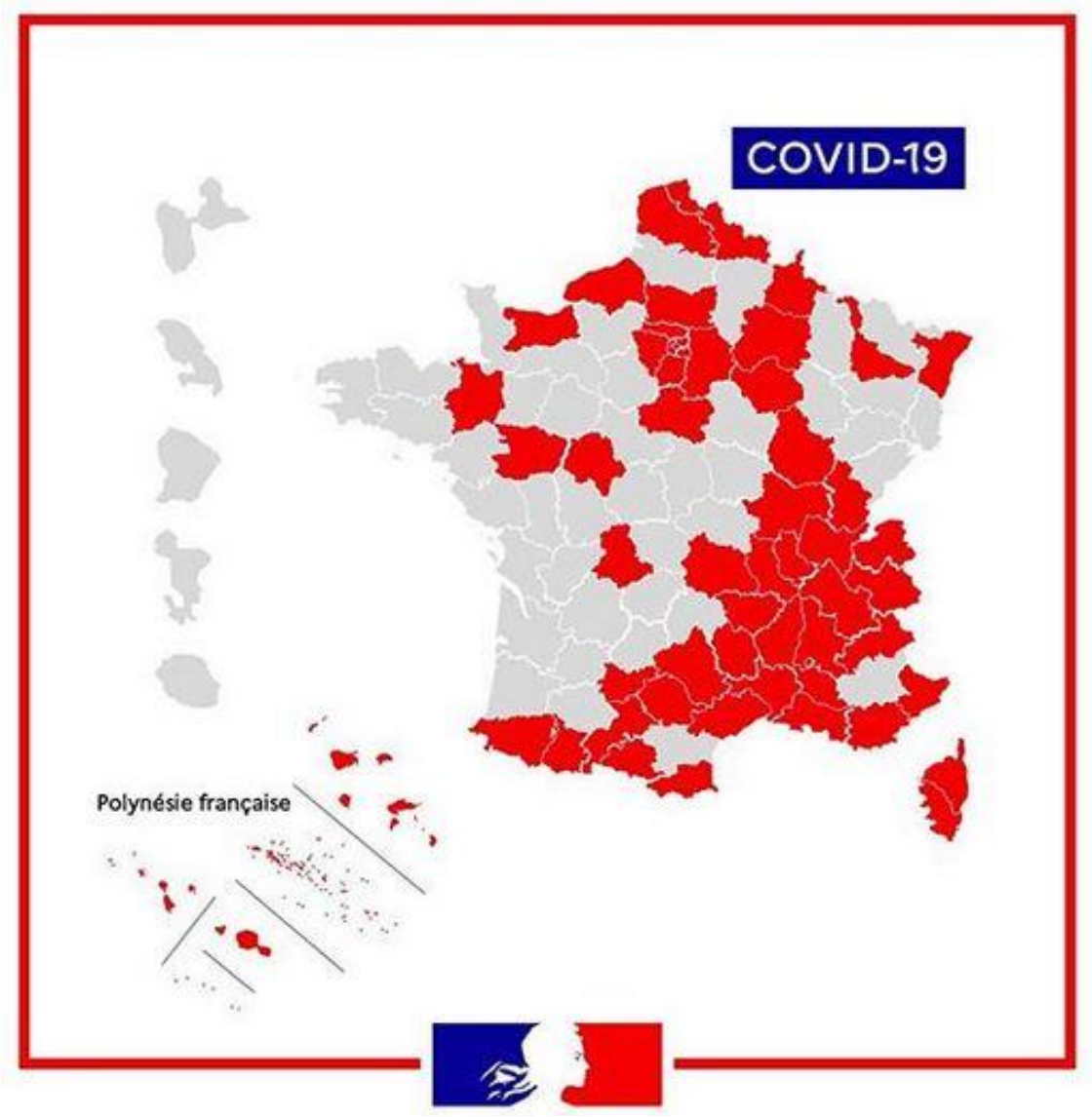

Source : Ministère des Solidarités et de la Santé, 24 octobre 2020

Suite à la déclaration de l'état d'urgence sanitaire sur l'ensemble du pays, la cartographie se simplifie. Le gouvernement crée deux catégories de territoires : état d'urgence sanitaire, et état d'urgence sanitaire accompagné de couvre-feu.

Notons que les tests virologiques n'ont été pris en compte dans la détermination du niveau d'alerte en lieu et place de la suspicion de contamination qu'à la veille de l'été, une fois la première vague passée. Entretemps, plutôt qu'un outil d'information et d'analyse, la carte a acquis une valeur légale et opérationnelle majeure. La classification détermine le niveau de quarantaine et les mesures à mettre en œuvre par les préfectures. Les conséquences sont énormes à tous points de vue, et différenciées spatialement. 
Ce bref récapitulatif démontre à quel point l'instabilité cartographique s'oppose à la régularité des indicateurs statistiques et à la stabilité des bases de données utilisées à l'amont. Cette stabilité est tardive: les bases de données ne se sont véritablement stabilisées qu'à partir de mai.

\section{Analyse critique : une non-gestion géographique ?}

Globalement, la logique du tableau de bord a produit des effets majeurs. (1) Le succès de ce moyen de communication a été phénoménal au point de transformer virtuellement hommes politiques et citoyens ordinaires en épidémiologistes-cartographes amateurs. Qui peut prétendre aujourd'hui planifier ses déplacements sans intégrer la variable coronavirus dans l'équation, que ce soit à l'échelle internationale, nationale ou locale ? (2) La dissociation des données épidémiologiques des variables démographiques a produit un biais récurrent dans la perception du risque. (3) Les cartographies thématiques simplifiées, par seuillage direct ou par classification, ont été inefficaces dans l'identification de clusters, en particulier en milieu rural. Les données distance-voisinage n'ont pas été intégrées faute d'algorithme approprié. (4) La diversité des représentations graphiques, la superposition des classements et leur succession rapide produisent aujourd'hui un effet de confusion.

Que retenir de ces outils cartographiques? De nombreux observateurs l'ont relevé, le placement du pays en quarantaine généralisée signifie un échec de la gestion de crise sur une base territoriale. Pourtant, toutes les analyses disponibles pointent vers une forte différenciation géographique entre clusters, quelle que soit la phase de développement de la pandémie, dans un contexte de forte comme de faible incidence. II ne s'agit pas ici de discuter de l'opportunité d'une décision de confinement général strict, simplement de constater que la gestion s'appuie sur une variable géographique incertaine. Avec pour résultat une mauvaise identification des zones d'intervention prioritaires.

La défaite historique de l'autonomie locale à laquelle nous assistons n'étonnera pas les historiens de l'administration d'État. Ce 
repli a toutefois acquis une dimension particulière avec la tenue d'élections municipales entachées d'un abstentionnisme record en mars et juin 2020. Le phénomène participe du processus général d'affaiblissement des communes au profit des EPCl et des régions. Les ARS ont joué pleinement le rôle de pôles-relais du pouvoir central, tel qu'il leur avait été assigné depuis leur création en 2010.

La cartographie à grande échelle n'intervient qu'en octobre, du moins dans la partie rendue publique des bases de données. Cette introduction est partiellement neutralisée par les circonstances : le pays tout entier est placé en alerte maximale. Le gouvernement sait déjà que la capacité d'extraction des collectivités locales du dispositif de contrôle des préfets est annihilée par la profondeur territoriale de la contamination. De plus, la neutralisation du local découle de l'incertitude technique des données domiciliées et du secret statistique qui impose la non-divulgation des données en valeur absolue.

Autre enseignement de l'exercice, le maillage le plus à même d'appréhender les phénomènes de contamination réelle (quartiers, îlots, foyers) reste hors champ. Le processus d'analyse cartographique a fonctionné sur un principe top-down : le maillage administratif prévaut; il détermine a priori la manière dont le coronavirus se déploie spatialement. Pourtant, un maillage bottomup aurait pu être envisagé, en partant du niveau spatial le plus fin : dès lors, la géographie de la COVID-19 se serait affranchie des contraintes administratives. Par des truchements cartographiques et statistiques classiques (fixité des frontières administratives, seuillages statistiques), la méthodologie officielle empêche l'identification des clusters précoces et ne permet d'en déterminer la dynamique spatiale que très imparfaitement.

Les villes ont été identifiées comme des foyers particulièrement actifs (par le nombre de personnes à prendre en charge), mais la capacité d'initiative des collectivités est restée limitée. Les plans de prévention élaborés dans les mairies sont des transpositions locales de directives et mesures adoptées au niveau national. Les niveaux infra-communal et infra-urbain ne sont pas traités : la diffusion réelle du virus entre quartiers et foyers reste hors de portée. Ce 
qu'expriment les cartes avant tout, c'est la mainmise politique et opérationnelle du système de santé sur le virus. L'analyse du déploiement de la COVID-19 dans l'espace est sacrifiée.

Figure 12. Conférence de presse du 7 mai 2020

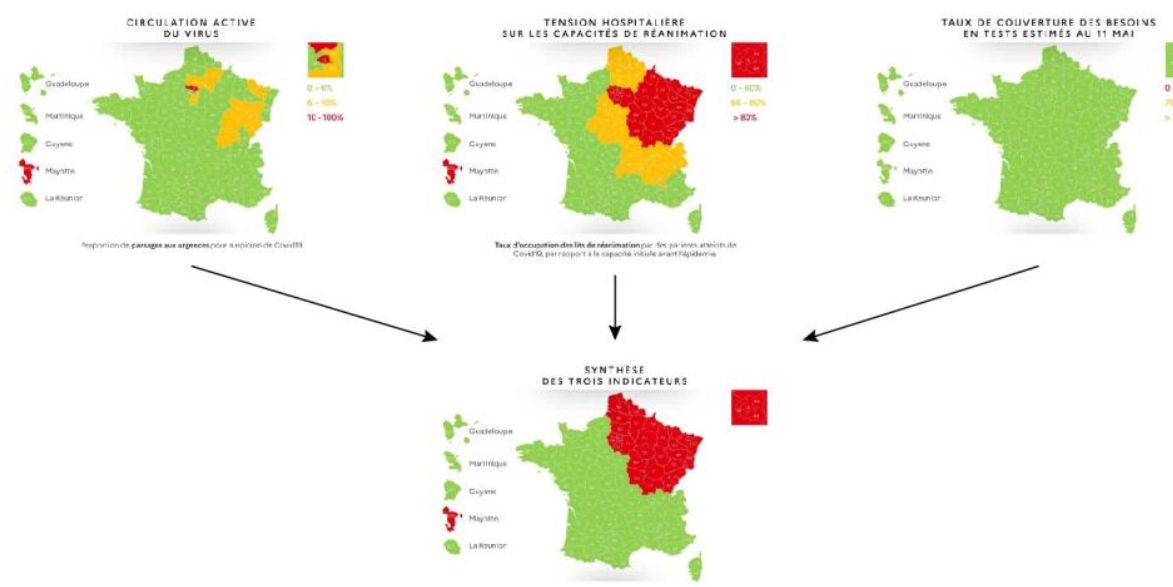

Source : Ministère des Solidarités et de la Santé

Ce type de cartographie est un très bon exemple de dégradation sérielle de l'information statistique. Partant d'indicateurs assez peu fiables, mais soigneusement sélectionnés, par strates successives et à travers des discrétisations obscures, on produit des indicateurs généraux qui sont eux-mêmes synthétisés dans un document final à haute valeur ajoutée politique. Cette perte de visibilité des données primaires produit des résultats parfois aberrants (zones d'alerte maximale côtoyant des secteurs supposés exempts). Le phénomène est accentué par l'effet " frontière » du maillage administratif.

\section{Conclusion : Retour vers la ville. Une épidémiologie urbaine à (ré)inventer}

Le confinement généralisé de la population sur l'ensemble du territoire national est une mesure dont les effets marquent profondément les esprits. La promiscuité à l'intérieur des domiciles, la pratique étendue du télétravail, l'isolement prolongé de personnes seules, l'absence d'exercice physique, l'impossibilité d'isoler les personnes contaminées au sein des foyers, sont parmi les événements qui ont transformé le rapport population-logement. Subrepticement, après 25 années de spéculation immobilière effrénée, les caractéristiques matérielles de l'habitat ont repris du 
poids dans les mécanismes de détermination de la valeur marchande des biens.

D'aucuns en ont conclu, probablement trop vite, que la ville moderne, dense, hypermobile, artificielle, ultra-dépendante de l'extérieur dans ses approvisionnements, était un modèle dépassé. Et voici le marché immobilier provincial, celui des départements ruraux profonds, pris dans un élan d'anticipation des (im)mobilités permanentes rendues possibles grâce au télétravail généralisé... Jusqu'à ce que l'on réalise à l'occasion de la seconde vague que les campagnes ont précocement développé des clusters localisés.

Il ne s'agit pas ici de discuter de la validité a priori de tel ou tel schéma de gestion territoriale prospective. Le diagnostic lui-même pose problème. Dès lors que la plupart des statistiques ne sont rendues disponibles qu'au niveau départemental, on ne peut apporter une réponse claire à la question qui sous-tend tous les scénarios du retour au rural : la ville a-t-elle facilité la propagation du virus au point de devenir un lieu de contagion privilégié ? Aucune donnée ne permet de valider l'hypothèse pour des raisons diverses, dont certaines déjà évoquées précédemment : les données locales manquent; les modes de contamination, liés aux modalités et types d'interactions sociales plus qu'aux lieux, sont désormais bien appréhendés à micro-échelle (celle des architectes), mais les effets de ces mécanismes à échelle intermédiaire (celle des urbanistes) sont mal connus; les populations à risque, en particulier âgées, ont leur propre logique, complexe, d'occupation et de pratique du territoire ; le profil des superinfecteurs est peu clair. En revanche, les situations de superpropagation liées à de vastes rassemblements font l'objet d'une attention croissante de la communauté scientifique (Al-Tawfiq \& Rodriguez-Morales, 2020; Kim, Ryu, \& Lee, 2018; Liu, Eggo, \& Kucharski, 2020; Zhang, Li, Wang, Li, \& Zhou, 2020).

La place centrale des établissements hospitaliers dans l'étalonnage de la pandémie en France introduit d'ailleurs un biais systémique: les malades sont comptabilisés dans les villes qui accueillent ces établissements. Mais le lien avec le lieu de contamination, qu'il soit domicile, lieu de travail, ou autre, n'est pas établi. Faute d'informations à caractère géographique, le coronavirus 
reste un agent pathogène hors-sol, dont le lien avec l'urbanisation n'est que supposé, sur la foi de relations statistiques faussement évidentes : les liens contagion-densité et contagion-mobilité.

Ainsi, à défaut de données statistiques robustes et d'outils d'analyse opérationnels, les systèmes géographiques à l'œuvre lors des contacts-contagions échappent encore à l'analyse. Par compensation, des liens de causalité sauvages sont inventés. Ici, comme dans le domaine cartographique, la pensée complexe fondée sur des données épidémiologiques fines, issues d'échantillons choisis et agrémentées de variables multiples à différentes échelles, cède la place à une pensée binaire.

Ces éléments de réflexion tendent à montrer que la cartographie a été entendue depuis le début comme un outil approximatif de communication et de gestion administrative plutôt que comme un instrument d'analyse d'un phénomène évolutif complexe. Les événements eux-mêmes accréditent la thèse. L'illusion cartographique et statistique continue de rassurer, mais l'outil est en soi inadapté à la maîtrise spatiale du développement épidémique. Un des plus importants points d'achoppement porte sur l'éviction des populations: dans la lignée des travaux d'épidémiologie à visée clinique, les patients-malades font l'objet de toutes les attentions, mais la relation avec les populations en bonne santé, non infectées, est pratiquement rompue. Le contexte démographique autant que géographique n'est pas ou peu pris en compte.

Les conflits de pensée autour du coronavirus dépassent largement le dialogue tumultueux entre scientifiques et politiques. Les désaccords méthodologiques entre disciplines sont profonds et les décalages d'approche qui en découlent conduisent au développement de stratégies d'exclusion de champs thématiques entiers, notamment à travers la concentration des financements de recherche. Empêcher l'émergence de travaux susceptibles de contredire ses propres résultats est le plus sûr moyen d'asseoir sa légitimité tout en évitant des échanges contradictoires pourtant indispensables à la vie de l'esprit (Arendt, 2013). Ainsi, à travers la logique des appels d'offres et celle des revues mainstream, des positions monopolistiques ont émergé au sein des milieux 
académiques. Ces phénomènes sont connus, étudiés depuis longtemps, mais la crise de la COVID-19 manifeste les dérives liées à ce mode de fonctionnement.

La logique des tableaux de bord et la faiblesse relative de la production scientifique sur la spatialisation du SARS-CoV-2 entérine une marginalisation de la géographie académique. Le phénomène est surprenant, mais il est désormais plus aisé d'en comprendre les raisons : face à la machine de communication officielle, les pensées alternatives ne pouvaient émerger... sauf à amplifier la confusion ou à brouiller les mots d'ordre officiels. Urgence et efficacité devaient primer -dans la logique de l'État.

Faute d'une organisation politico-administrative solide qui fasse contrepoids aux départements et aux régions, les villes ont souffert de leur émiettement. Elles le payent au prix fort: la pandémie entérine leur inexistence dans le champ opérationnel de la gestion de crise (si l'on excepte leur rôle de police). Derrière la défaite magistrale de la géographie à laquelle nous assistons, se cache un effondrement des communautés locales devant les défis épidémiologiques globaux.

Il est important de situer dans un cadre plus large les péripéties de notre projet de suivi de la propagation de l'épidémie au travers des eaux usées d'un réseau d'assainissement. Il s'agit d'un projet très peu dispendieux eu égard aux budgets dépensés par ailleurs pour analyser le phénomène coronavirus en France. L'objectif est d'élaborer une cartographie issue d'une toute autre coproduction de l'ordre social et naturel que celle qui a émergé jusqu'à présent. L'initiative porte sur l'identification des îlots d'habitation d'où émergent les traces virales. Une représentation de l'épidémie à cette échelle pourrait permettre aux autorités locales de répondre à la crise et de regagner une marge d'autonomie. Les bénéfices économiques et sociaux attendus permettraient d'éviter les séries de confinements-déconfinements chaotiques généralisés auxquels nous assistons actuellement. Mais ils seraient obtenus au prix d'un affermissement du pouvoir local. Or, les mécanismes d'épistémologie civique qui prédominent jusqu'à présent se construisent quasi 
exclusivement à l'échelon national. L'alliance entre scientifiques et administration se réalise plus facilement à ce niveau.

Notre projet ne peut aider à lutter contre l'épidémie que dans les seuls lieux où des réseaux d'assainissement existent. II ne sera donc pas utile dans les régions rurales dépendant de fosses septiques. Sa mise en œuvre s'inscrit de manière privilégiée dans les milieux urbains. II contribuera à une coproduction d'un pouvoir territorial exercé par les maires ou toute autre institution ou organisme susceptible d'exercer des arbitrages locaux, alors que la crise a jusqu'à présent suscité une coproduction d'un biopouvoir exercé par le gouvernement national de façon très centralisée - cette centralisation est accentuée par le recours au Conseil de défense en lieu et place du Conseil des ministres; les réunions du Conseil de défense ne donnent pas lieu à des comptes rendus.

La théorie de l'acteur réseau (Latour, 1987) a démontré de longue date la façon dont divers acteurs et actants doivent être enrôlés pour permettre l'émergence de faits scientifiques et de coproductions stabilisées. Le SARS-CoV-2 est aujourd'hui un actant enrôlé par un réseau d'acteurs qui coproduisent une cartographie de l'épidémie cohérente avec une gestion nationale centralisée de la crise sanitaire. Notre projet propose d'enrôler le même virus dans un réseau d'acteurs qui coproduisent une cartographie de l'épidémie cohérente avec le niveau d'échelle où s'exerce la propagation du virus. Cette cartographie est compatible avec une gestion décentralisée de la crise sanitaire.

\section{Liste des références}

Al-Tawfiq, J. A., \& Rodriguez-Morales, A. J. (2020). Super-spreading events and contribution to transmission of MERS, SARS, and SARS-CoV-2 (COVID-19). Journal of Hospital Infection, 105(2), 111-112. Retrieved from https://doi.org/10.1016/i.jhin.2020.04.002. doi:10.1016/j.jhin.2020.04.002

Arendt, H. (2013). La vie de l'esprit. Paris: PUF. 
Becher, T., Trowler, P.R., 2001. Academic Tribes and Territories, 2nd ed. Open University Press, Buckingham.

Bbcworld. (2020). How a misleading coronavirus map went global. Retrieved from https://www.bbc.com/news/world-51504512

Black, J. (1997). Maps and Politics. Chicago: University of Chicago Press.

Boria, E. (2013). Geographers and Maps: A Relationship in Crisis. L'Espace Politique, 21(3).

Callon, M., 1986. Eléments pour une sociologie de la traduction. L'année sociologique $36,170-208$.

Chen, Y., Chen, L., Deng, Q., Zhang, G., Wu, K., Ni, L., Yang, Y., Liu, B., Wang, W., Wei, C., Yang, J., Ye, G., Cheng, Z., 2020. The presence of SARS-CoV-2 RNA in the feces of COVID-19 patients. Journal of medical virology 92, 833-840.

Crampton, J. W. (2001). Maps as social constructions: power, communication and visualization. Progress in Human Geography, 25(2), 235-252. Retrieved from <Go to |S|>://WOS:000168255400004. doi:10.1191/030913201678580494

Darques, R. (2015). Mapping and Managing Cities through Information Systems. In Essais critiques sur la ville (pp. 231-282). Genève: Infolio.

Dodge, M., Kitchin, R., \& Perkins, C. (Eds.). (2009). Rethinking Maps. London-New York: Routledge.

Etalab. (2020, 2020-06-09). Comment les administrations ont collaboré à l'ouverture des données du Coronavirus : le cas français | Le blog d'Etalab. Retrieved from https://www.etalab.gouv.fr/comment-les-administrations-ontcollabore-a-louverture-des-donnees-du-coronavirus-le-cas-francais

Genevois, S. (2020). La cartographie des épidémies entre peur de la contagion et efforts de prévention. Exemple à travers la diffusion du coronavirus. Retrieved from http://cartonumerique.blogspot.com/2020/01/cartographie-epidemies.html

Geraghty, M. N. K. B., \& Estella, M. (2020). Geographical tracking and mapping of coronavirus disease COVID-19/severe acute respiratory syndrome coronavirus 2 (SARS-CoV-2) epidemic and associated events around the world: how 21st century GIS technologies are supporting the global fight against outbreaks and epidemics. International Journal of Health Geographics, 19(1), 1-12. Retrieved from https://ijhealthgeographics.biomedcentral.com/articles/10.1186/s12942-020-00202-

8\#citeas. doi:doi:10.1186/s12942-020-00202-8

Gouvernement.fr. (2020). Info coronavirus covid 19 - carte et donnees covid 19 en france. Retrieved from https://www.gouvernement.fr/info-coronavirus/carte-etdonnees

Huff, D. (1993). How to Lie with Statistics. New York-London: Norton \& Company. 


\section{France?}

Jasanoff, S., 2005. Designs on nature : science and democracy in Europe and the United States. Princeton University Press, Princeton, N.J.

Jasanoff, S., 2004. States of knowledge : the co-production of science and social order, International library of sociology. Routledge, London ; New York.

JohnsHopkins. (2020). COVID-19 Map. Retrieved from https://coronavirus.jhu.edu/map.html

Kim, Y., Ryu, H., \& Lee, S. (2018). Agent-Based Modeling for Super-Spreading Events: A Case Study of MERS-CoV Transmission Dynamics in the Republic of Korea. International Journal of Environmental Research and Public Health, 15(11), 2369. Retrieved from https://www.mdpi.com/1660-4601/15/11/2369.

Latour, B., 1987. Science in Action. Harvard University Press, Cambridge, Massachusetts.

Liu, Y., Eggo, R. M., \& Kucharski, A. J. (2020). Secondary attack rate and superspreading events for SARS-CoV-2. The Lancet, 395(10227), e47. Retrieved from https://doi.org/10.1016/S0140-6736(20)30462-1. doi:10.1016/S01406736(20)30462-1

Medema, G., Heijnen, L., Elsinga, G., Italiaander, R., Brouwer, A., 2020. Presence of SARS-Coronavirus-2 RNA in Sewage and Correlation with Reported COVID-19 Prevalence in the Early Stage of the Epidemic in The Netherlands. Environ. Sci. Technol. Lett. 7, 511-516. https://doi.org/10.1021/acs.estlett.0c00357

Ministère des Solidarités et de la Santé. (2020, 2020-06-16). Etalab-covid-19dashboard. Suivi de l'épidémie de COVID-19 en France. Retrieved from http://dashboard.covid19.data.gouv.fr

Monmonier, M. (1991). How to lie with maps. Chicago: University of Chicago Press.

Monmonier, M. (2005). Lying with Maps. Statistical Science, 20(3), 215-222.

Occitanie, A. (2020). Coronavirus : dernier point de situation en Occitanie. Retrieved from https://www.occitanie.ars.sante.fr/coronavirus-dernier-point-desituation-en-occitanie-0

Olsson, G. (2007). Abysmal: A Critique of Cartographic Reason. Chicago: University of Chicago Press.

Ouestfrance. (2020, 2020-02-25). CARTE. Épidémie de coronavirus : quels sont les hôpitaux mobilisés en France ? Retrieved from https://www.ouestfrance.fr/sante/virus/coronavirus/carte-epidemie-de-coronavirus-quels-sont-leshopitaux-mobilises-en-france-6752383

Santé Publique France. (2020a). data.gouv.fr. Retrieved from https://www.data.gouv.fr/fr/datasets/donnees-hospitalieres-relatives-a-lepidemiede-covid-19/ 
Santé Publique France. (2020b). Géodes - Santé publique France - Indicateurs : cartes, données et graphiques. Retrieved from https://geodes.santepubliquefrance.fr/\#c=indicator $\& \mathrm{f} 2=0 \& \mathrm{i}=$ covid hospit incid.inc id hosp\&i2=sursaud corona quot.prop corona hospit sau q\&s=2020-06$15 \& \mathrm{~s} 2=2020-06-14 \& \mathrm{t}=\mathrm{a} 01 \& \mathrm{t} 2=\mathrm{a} 01 \& \mathrm{view}=\operatorname{map} 2$

Santé Publique France. (2020c). Géodes. Géo-données en santé publique. Retrieved from http://geodes.santepubliquefrance.fr

Supiot, A. (2015). La gouvernance par les nombres. Paris: Fayard.

Tang, A., Tong, Z.D., Wang, H.L., Dai, Y.X., Li, K.F., Liu, J.N., Wu, W.J., Yuan, C., Yu, M.L., Li, P., Yan, J.B., 2020. Detection of Novel Coronavirus by RT-PCR in Stool Specimen from Asymptomatic Child, China. Emerging infectious diseases 26, 13371339.

Trottier, J., Darques, R., Ait Mouheb, N., Partiot, E., Bakhache, W., Deffieu, M.S., Gaudin, R., 2020. Post-lockdown detection of SARS-CoV-2 RNA in the wastewater of Montpellier, France. One Health 10, 100157. https://doi.org/10.1016/j.onehlt.2020.100157

Wood, D. (2010). Rethinking the Power of Maps. New York-London: Guilford Press.

Wood, D., \& Fels, J. (2008). The natures of maps: Cartographic constructions of the natural world. Chicago: University of Chicago Press.

World Health Organization. (2020a). Coronavirus Disease (COVID-19) Situation Reports. Retrieved from https://www.who.int/emergencies/diseases/novelcoronavirus-2019/situation-reports/

World Health Organization. (2020b). WHO Coronavirus Disease (COVID-19) Dashboard. Retrieved from https://covid19.who.int

Worldmapper. (2020, 2020-06-07). Map animation: Covid-19's spread across the world | Worldmapper. Retrieved from https://worldmapper.org/map-animationcovid19/

Wu, Y., Guo, C., Tang, L., Hong, Z., Zhou, J., Dong, X., Yin, H., Xiao, Q., Tang, Y., Qu, X., Kuang, L., Fang, X., Mishra, N., Lu, J., Shan, H., Jiang, G., Huang, X., 2020. Prolonged presence of SARS-CoV-2 viral RNA in faecal samples. The Lancet Gastroenterology \& Hepatology 5, 434-435. https://doi.org/10.1016/S24681253(20)30083-2

Zhang, Y., Li, Y., Wang, L., Li, M., \& Zhou, X. (2020). Evaluating Transmission Heterogeneity and Super-Spreading Event of COVID-19 in a Metropolis of China. International Journal of Environmental Research and Public Health, 17(10), 3705. Retrieved from :

https://www.mdpi.com/1660-4601/17/10/3705. 